\title{
O Processo Psíquico sob a ótica Fenomenológica
}

Melissa Garcia Tamelini ${ }^{1}$

\section{Resumo}

O artigo propõe uma interpretação da categoria biográfica processo, conceito clássico desenvolvido por Karl Jaspers, sob a ótica da Psicopatologia Fenomenológica. Inicialmente, faz uma breve apresentação de proposições chaves da centenária obra Psicopatologia Geral, que confluirão para a definição de processo psíquico. Em um segundo momento, o artigo localiza os distintos planos de observação das duas abordagens psicopatológicas, a de Karl Jaspers e a Fenomenológica, contrastando suas metodologias. Finalmente, propõe uma leitura fenomenológica, temporoespacial por excelência, de processo, buscando apontar microscopicamente, no locus estrutural, o seu estatuto.

Palavras-chave: Psicopatologia Fenomenológica; Karl Jaspers, Psicopatologia Geral"; Categorias Biográficas; Processo Psíquico.

\section{A Phenomenological View to the Process}

\begin{abstract}
This paper proposes an interpretation of biographical process, a classical concept developed by Karl Jaspers, from the point-of-view of Phenomenological Psychopathology. It begins with a brief introduction to the key concepts of Jaspers' centennial work General Psychopathology that found the definition of Process. It then looks at the different psychopathological approaches, Jaspers' and Phenomenology, and compares their methodologies. To conclude, the paper proposes a phenomenological reading - quintessentially a time-spatial one - of the process, attempting to point out, microscopically, at the structural locus, its statute.
\end{abstract}

Keywords: Phenomenological Psychopathology; Karl Jaspers; General Psychopathology; Biography, Process.

\footnotetext{
${ }^{1}$ Médica Psiquiatra. Membro da Sociedade Brasileira de Psicopatologia Fenômeno-Estrutural. Médica Assistente do Instituto de Psiquiatria do Hospital das Clínicas da Faculdade de Medicina da USP. E-mail: melissa@fenomenoestrutural.com.br
} 
Ainda que os estudos sobre a esquizofrenia partam de casos clinicos, Binswanger aqui parte da linguagem desenvolvida pela sociedade como pela psicopatologia clínica em seu comércio com as formas do Dasein - já que os projetos-de-mundo que abrigam a linguagem usual são "nossa morada espiritual original". O objetivo não permanece aqui menos idêntico: compreender as transformações da Presença que sustentam estas formas, reduzidas aos sintomas pela psicopatologia clinica, como fenômenos antropológicos, direções significativas gerais do serhumano, ameaças imanentes a toda Presença humana.

(Tatossian, 2006, p. 68)

\section{Introdução}

Em 1913, Karl Jaspers publica seu trabalho intitulado Psicopatologia Geral (Jaspers, 2000). Nestes cem anos, a Psiquiatria notabilizou-se pelo avanço tecnológico, sobretudo no que tange ao arsenal da farmacologia e de investigação do substrato neuronal. Tais progressos, incorporados pela lógica positivista dominante, desembocaram na busca incessante e otimista de pressupostos como universalidade e especificidade. Apesar de ressalvas declaradas, os manuais diagnósticos tornaram-se o reflexo e o arauto de uma Psiquiatria com anseios por um assento definitivo em domínios ditos "científicos".

Neste cenário, a Psicopatologia resignou-se a um papel menor, acanhada perante um poderoso mainstream que requer reparos simplistas e imediatos para justificar seus diagnósticos e condutas terapêuticas. $O$ bem-vindo progresso trouxe seus efeitos colaterais e, infortunadamente, assistiu-se a um apaziguamento da fértil inquietação diante das complexidades inerentes ao campo epistemológico da Psicopatologia (Andreasen, 2007). Escassearam-se os estudos qualitativos (e de qualidade, de modo geral), enquanto abundam estudos quantitativos, não raro tautológicos, peças de um corpo de evidências muito menos sólido do que se declara, cambaleante diante de uma arguição mais rigorosa, em virtude de amputações inadmissíveis do real.

A celebração do centenário da obra de Karl Jaspers traz a possibilidade de revisitar e reverenciar a já sua bem estabelecida magnitude. A ordenação, sobretudo metodológica, feita com astúcia e rigor pelo jovem médico, que após 
tal trabalho se debruçaria sobre questões filosóficas, continua a nortear a Psicopatologia e a Psiquiatria (Jablensky, 2013). Mesmo em trabalhos de filiação diversa, como no caso da Psicopatologia Fenomenológica, as categorias jasperianas são invocadas. Exemplo disso são os estudos de caso agrupados na obra "Esquizofrenia", nos quais, após uma minuciosa discussão antropológica (ou dasein-analítica), o autor, Binswanger, reserva espaço para a pergunta célebre, que emerge da obra jasperiana: trata-se de um processo ou de um desenvolvimento?

A data comemorativa também inspira novas investigações e, nesse sentido, o presente artigo propõe uma interpretação da categoria biográfica processo psíquico sob a ótica da Psicopatologia Fenomenológica. Ou seja, intenta apontar microscopicamente, no locus estrutural, seu estatuto pressupondo que, à luz da concepção fenomenológica, possam ser encontradas algumas chaves de entendimento e compreensão deste curso temporal típico. Antes, porém, sucintamente revisa alguns conceitos jasperianos, inclusive o de processo, no intuito de embasar a sua relevância, mesmo em vertentes distintas de investigação psicopatológica.

\section{Psicopatologia Geral, Categorias Biográficas e Processo Psíquico}

Na Psicopatologia Geral, Karl Jaspers enfatiza a "pluridimensionalidade" do fenômeno patológico e sua decorrência natural, a multiplicidade metodológica. A obra é dividida em grandes sessões, com distintos escopos: inicialmente, a discriminação do fenômeno psicopatológico (tanto aspectos "subjetivos", as chamadas vivências, como "objetivos", os rendimentos e manifestações expressivas), a seguir o estabelecimento de vínculos causais entre tais fenômenos e, por fim, a inserção desses elementos em totalidades.

A primeira parte, denominada Fenomenologia, ocupa-se das vivências internas dos pacientes, almejando conhecê-las da forma mais próxima possível da experiência original (Jablensky, 2013). A preocupação fundamental é de ordem descritiva, tarefa dissonante daquela que se proporá a Psicopatologia Fenomenológica de L. Binswanger, Minkowski, Gebsattel e outros, razão pela qual Jaspers é situado como um autor pré-fenomenólogo (Tatossian, 2006). Assim, apesar da coincidência nominal, há diferenças marcantes entre Jaspers as demais propostas ditas "fenomenológicas" e o próprio Jaspers reconhecia tal distinção.

Após a discriminação de diversos protótipos formais de vivências, Jaspers discute o encadeamentos causal entre eles, opondo dois tipos ideais: 
"relações compreensíveis" (o psíquico surge do próprio psíquico) e "relações explicativas" (o psíquico surge do corporal). A relação compreensível é facilmente empatizável: a conexão se vive como algo evidente e que não necessita de maiores comprovações. Já na vertente explicativa, típica das ciências naturais, a articulação entre as vivências se estabelece apenas se dispusermos de certa informação científica que a apoie, uma vez que não é empatizável (o recurso explicativo discrimina relações de causa e efeito).

Na arquitetônica da Psicopatologia Geral, na medida em que se caminha rumo às totalidades, os axiomas anteriores são retomados, como pré-requisitos fundamentais para o exame do global. O célebre capítulo da Biografia, do rol das totalidades, amplia o leque de categorias e sistematiza a clássica oposição entre desenvolvimento e processo, que debutava na obra jasperiana em 1910, em um artigo sobre o delírio de ciúmes (Jaspers, 1977).

As categorias biográficas propõem distintas modalidades de projeção do fenômeno psíquico sobre o percurso temporal, "alçando o tempo, em suas transformações contínuas, como ordenador de um conjunto de conceitos em psicopatologia" (Messas, 2004, p.46). Apoiado nos conceitos de compreensão/explicação e reversibilidade, Jaspers separa a série "históricovital" das "séries típicas de curso", ambas com subdivisões internas. A primeira marca a progressão histórica do sujeito sob a égide da gênese compreensiva e abarca conceitos como "primeiras vivências", "adaptação" e "crise", que esculpem o percurso individual de modo único e irreversível e que, em conjunto, irão confluir para a grande categoria, o "desenvolvimento da personalidade".

O diálogo com a Psicopatologia Fenomenológica, propósito aqui desenvolvido apenas com o conceito de processo psíquico, parece ser uma interessante perspectiva de investigação também no caso das modalidades histórico-vitais. O próprio Jaspers (2000) a autorizaria, de certo modo, ao afirmar que "o psíquico que surge do psíquico não se sustenta em si mesmo". Segundo Climent (2003, p. 59): “deve-se supor algum mecanismo subjacente que estabeleça a relação e a oriente, ainda que não se possa ter consciência de onde e como joga esse mecanismo". Justamente a estrutura temporoespacial, primeira síntese estável da consciência (ainda que em expansão, em condições normais), pode ser considerada esse mecanismo subjacente que confere identidade e constitui-se imprescindível para o provimento da habitualidade formal e, em certa parte, temática. Dessa maneira, a regularidade típica das séries compreensivas requereria condições mínimas de integridade estrutural, uma vez que esta seria essencialmente a sua totalidade provedora $\mathrm{e}$ mantenedora. 
Em relação às "séries típicas de curso", Jaspers afirma: "a transformação permanente do organismo em seu todo apresenta-se como consequente às idades e manifesta-se em séries típicas que constituem um curso: ataques, fases, processos"(Jaspers, 2000, p. 822). O elemento agregador aqui é a emergência do "incompreensível", abrindo diálogo com a ordem biológica, endógena, sempre vigente e simultânea à lógica psicológica. Para Jaspers, o incompreensível não remete apenas a fenômenos patológicos. É o próprio qualificador da passagem do tempo no psiquismo, dada, por exemplo, pelas distintas fases cronológicas e suas configurações formais características. O conceito de estrutura psíquica também se prestaria ao aprofundamento das diferenças formais entre as distintas fases etárias, ou seja, suas correlações em âmbito estrutural, o que daria ensejo a elaboração sistemática da estrutura temporoespacial típica da infância, adolescência e senescência, por exemplo.

Jaspers opõe nas "séries típicas de curso", considerando o critério da reversibilidade, ataques, fases e períodos aos processos. Todos marcados pela inflexão na cadeia biográfica que, ao interromper a continuidade temática e formal, de maneira definitiva ou não, faz necessário o apelo ao recurso explicativo.

Do lado da reversibilidade, afirma:

A vida psíquica altera-se em fases que interrompem a existência. Quando essas fases se acentuam, costumam se tornar objeto de investigação psicopatológica; quando são breves (minutos a segundos), falamos em ataques; quando retornam em intervalos de tempos regulares, com a mesma forma, falamos em períodos. Ataque, fase e período são conceitualmente endógenos; ignora-lhes quase sempre a causa. (Jaspers, 2000, p. 829)

O processo, por sua vez, é definido "quando contrário ao desenvolvimento existencial que até o momento se verificou, surge alguma coisa nova, resultado da alteração da vida psíquica, de caráter permanente" (Jaspers, 2000, p. 829). Aqui "o psiquismo assume um aspecto novo, com uma redefinição e reacomodação das características anteriores" (Messas, 2004, p. 46). $\mathrm{Ou}$ ainda, a "transformação psicologicamente incompreensível da personalidade, sem base somática conhecida, caracteriza o processo psíquico" (Alonso-Fernandez, 1979, p. 194). A esquizofrenia é a representante maior de tal evolução e tratar dos aspectos psicopatológicos da evolução processual significa abordar uma das características mais marcantes dessa patologia.

No processo psíquico, "a irrupção de elementos heterogêneos, incompreensíveis determinam uma espécie de cotovelo na linha evolutiva da 
personalidade" (Alonso-Fernandez, 1979, p. 194). “O novum processual é caracterizado pela presença de um ou vários traços, distribuídos em três ordens distintas: a da forma anômala da vivência, a dos temas que carecem de sentido histórico-vital e a da desintegração da ordem estrutural"(Alonso-Fernandez, 1979, p. 198).

Uma vez apresentada a definição de processo psíquico, algumas considerações. Primeiro, a respeito do legado da Psicopatologia Geral. Diversas proposições lá desenvolvidas não enfrentaram concorrência à altura nos cem anos transcorridos desde o surgimento da obra e continuam nucleares no campo da Psicopatologia Clínica. As categorias biográficas, por exemplo, constituem uma ordenação sucinta e eficaz da tipicidade formal, patológica ou não, no percurso histórico, destacando o fator temporal como elemento imprescindível na análise dos fenômenos da consciência. A segunda consideração versa a respeito do campo no qual estão inseridas as propostas conceituais da Psicopatologia Geral. Jaspers privilegia o universal, em detrimento do particular, para o qual se exigiria uma análise calcada em casos clínicos, o que, de fato, não existe na obra, assim como o vivenciado, e não o vivido ou a investigação das "condições de possibilidade", justamente o propósito da Psicopatologia Fenomenológica. Tal abordagem era criticada por ele, que a considerava uma abstração a exploração nos fundamentos da consciência, mais distanciados da experiência subjetiva do paciente, ou seja, menos passíveis de averiguação "objetiva" (Jaspers, 2000). Entretanto, ao abandonar precocemente os estudos psicopatológicos, ele não dialogou profundamente com a literatura fenomenológica, cujo mais contundente desenvolvimento foi posterior à publicação da obra em questão.

Para a interlocução entre a abordagem jasperiana e a fenomenológica, é necessário localizar os discursos e mapear as metodologias, a partir das quais brotam seus construtos e, somente em um segundo momento, proceder em direção à empreitada proposta, que parecerá, assim, ainda mais justificável depois de bem situados em planos distintos os dois projetos psicopatológicos. Tal exercício parece mais fértil do que a simples comparação ou a defesa ardilosa da superioridade de uma das abordagens e, mais, ambas podem lucrar com o enriquecimento da apreciação do objeto de estudo que compartilham, mas que visualizam de perspectivas e com pontos cegos heterogêneos. A Psicopatologia Fenomenológica não concorre com a jasperiana, nem reivindica o seu lugar na seara psicopatológica, mas, ao operar com instrumento de "precisão", pode refinar os seus construtos. Assim, iluminados por luz fenomenológica, estes passam a ser tratados não como formulações fossilizadas, mas como pontos de partida para novas investigações, como a aqui proposta dissecção do processo psíquico até a sua ossatura estrutural. A desintegração irreversível da linearidade compreensiva, esmiuçada pela ótica estrutural, 
amplia a validade do conceito de processo, revela seu sentido essencial e contribui, inclusive, para separações diagnósticas, prognósticas e terapêuticas. A Psicopatologia Fenomenológica, por sua vez, ao justificar a relevância de categorias semiológicas, expande seu escopo e dialoga com o universal.

É importante ressaltar que é a Psicopatologia Clínica que preestabelece o objeto de estudo da fenomenologia. Lanteri-Laura (1982, p. 55) aponta uma "aporia fundamental", a de que a fenomenologia só pode ser desempenhada "na condição de aceitar o conhecimento psiquiátrico como ele é". Exemplo disso é o que aqui se desenvolve: para o estudo das "condições de possibilidade" temporoespaciais do processo, deve-se partir da categoria processo, definida e fundamentada previamente em outros domínios epistemológicos. A proposta de traçar tais correlações estruturais é endossada pela obra de autores como Binswanger, por exemplo, que se utiliza da nomenclatura biográfica jasperiana em meio a uma profunda discussão fenomenológica.

\section{Contribuição da Psicopatologia Fenomenológica ao conceito de Processo Psíquico}

Jaspers concebe a noção de processo psíquico, do rol das totalidades, entrelaçando os planos da fenomenologia e das relações de conexão causal. $\mathrm{O}$ exemplo paradigmático do ponto de inflexão do leito compreensivo é a vivência delirante primária. Essa "novidade" formal, ainda que descrita em seus atributos "epidérmicos", como incorrigibilidade, não compartilhamento, convicção extraordinária e impossibilidade de conteúdo, pressupõe mais essencialmente, como Jaspers é categórico ao afirmar, uma modificação global da personalidade (Walker, 1991). Nota-se, assim, uma certa sobreposição conceitual entre processo e delírio, uma vez que o "fenômeno de "tornar-se delirante" leva implicitamente a ruptura da continuidade significativoestrutural na biografia do ser" (Alonso-Fernandez, 1979, p. 197), ou seja, a modificação global da personalidade, atributo maior do processo. Dessa maneira, o delírio não seria o ponto zero do processo, nem mesmo sua causa, mas uma "mera" expressão formal da fratura já consolidada em ordem mais elementar da consciência, a mesma que se expressa no plano longitudinal, biográfico, como um processo. Binswanger (1968) endossa tal posição ao afirmar que diante da "manifestação de um sintoma esquizofrênico massivo", não estaríamos presenciando o "surgimento" da esquizofrenia, mas teríamos mais propriamente diante de nós o resultado "pronto". 
Entretanto, a modificação global implicada nos dois conceitos não está precisada na Psicopatologia Geral e Jaspers, ao se manter no plano do vivenciado, esquiva-se de prosseguir em direção aos seus subsídios ontológicos, mesmo reconhecendo de alguma maneira a insuficiência daquele. $\mathrm{O}$ exame deste sítio primário é justamente a tarefa fenomenológica. Sejam patológicos ou não, é o arcabouço fundamental que garante a aparição de fenômenos no plano da experiência vivenciada, a chamada "estrutura vivida". Evidentemente, a fenomenologia psiquiátrica se vale do vivenciado, uma vez que esse é porta de acesso ao vivido, objeto por excelência daquela, cuja via régia de revelação é o contato interpessoal. Porém, diferentemente da semiologia, que não pode prescindir da coleta minuciosa de sintomas, ela pode eleger um único sintoma/sinal como fenômeno paradigmático para estudo e validação de uma totalidade.

O privilégio é da síntese estruturada, dos constituintes temporoespaciais e do estudo calcado no caso clínico. Dessa maneira, a esquizofrenia, patologia por excelência detentora do selo processual,

poderá ser vista como modificações específicas da estrutura a
priori do Dasein e, o que chamamos em outro contexto de
sintoma, adquirirá desde a perspectiva da unidade ser-mundo,
o caráter de fenômeno abarcador do mundo e de si-mesmo. O
quadro da esquizofrenia parecerá uma estrutura unitária e
plena de sentido, sem que nada "aconteça ao acaso". (Dörr
Zegers, 1995, p. 49)

Passemos, então, ao exame do selo estrutural do processo psíquico. Como foi visto, "a continuidade de sentido não apenas guarda relação com os conteúdos, mas com a estrutura, na medida em que está condicionada por uma ordenação estrutural ou formal da trama psíquica" (Alonso-Fernandez, 1979, p. 198); assim, é na estrutura vivida que encontraremos a raiz primordial da desintegração processual. Por estrutura, entende-se o "arcabouço íntimo, fornecedor das condições de possibilidade da própria consciência e, com ela, da mesma existência"; "o nascedouro irredutível da vida mental, antes do qual apenas conjecturas de ordem metafísica seriam possíveis é a sua coordenada temporoespacial" (Messas, 2010, p. 1).

Comecemos pela análise da temporalidade. A leitura estrutural aqui proposta será norteada pela possibilidade de ocorrerem desequilíbrios dialéticos nas proporções antropológicas temporoespaciais (Blankenburg, 1982). A impressão digital processual é formada pela tipicidade desta desproporção e seu consequente dano. A sua irreversibilidade conceitual (refletida nos modestos anseios de profunda transformação das formas esquizofrênicas) justifica-se, estruturalmente, pela magnitude da desarticulação nesta vertente 
fundamental da consciência. Diferentemente de outras patologias que também alteraram gravemente a temporalidade, como a mania e melancolia, nos processos esquizofrênicos há uma desintegração da própria engrenagem. Assim, mais que a simples desproporção em favor de uma estase temporal, há a perda das amarras com as outras estases, culminando com uma temporalidade anquilosada, inviabilizadora de anseios genuínos de transcendência: "a desarticulação das instâncias temporais deixa a consciência ilhada em um presente não autêntico, fadado a esgotar-se em si mesmo" (Tamelini, 2012, p. 7). $\mathrm{O}$ insulamento da consciência nesse presente inautêntico retroalimenta-se de alguma forma, e, quanto mais preponderar, mais dominante tende a ser.

No caso Ellen West, Binswanger fala de uma "fixação da existência", dada pelo esfacelamento da temporalidade em suas estases e a ampla independência das mesmas, com o resultado de que "o tempo", no fundo, deixa completamente de "fluir". A vida esquizofrênica tende a uma manutenção estática, em um presente de formas eternas, acabadas, desconectado das duas pontas da temporalidade. O desvio processual é o resultado dessa temporalidade desarticulada, sem os subsídios históricos e sem direcionamento consistente ao devir, ou seja, "a suspensão da possibilidade de temporalização constante e extensiva" (Binswanger, 1968, p. 185).

Dessa forma, a temporalidade no processo, mais que uma preponderância quantitativa, é uma desvirtuação qualitativa, desembocando no vazio, expresso pelo "progressivo estreitamento, perda de potência e mundanização" da existência (Binswanger, 1968, p. 191) ou ainda, clinicamente, com autismo e "atos em curto-circuito" (Minkowski, 2000). As formas esquizofrênicas (ou processuais) colocam em questão “a consequência ou continuidade da experiência, dentro da medida ou da contradição de alternativas estéreis, da ausência de tema e da irrealização do curso da vida" (Binswanger, 2005, p. 21).

Pode-se supor a coexistência de zonas de temporalidade íntegra junto às de marca processual, mas, como regra geral, quanto maior for a dimensão da temporalidade deste segundo modus operandi, com um presente marcado pela ausência de interdigitações retentivas e protentivas, menor a possibilidade de autenticidade e transformação.

A espacialidade nos processos também é marcada por desproporções antropológicas. Minkowski (2005) assinala a sobreposição do espaço escuro sobre o claro, ou seja, um "acavalamento" entre duas modalidades, culminando com alterações da experiência de fronteira do eu, diminuição da distância vivida e alteração da amplitude vital, com a "substituição da casualidade, 
coincidência e acaso por um mundo hiper-significado, hostil, repleto de causalidade e determinações" (Tamelini, 2012, p. 7).

Outras desproporções são descritas neste âmbito, como a da verticalidade em detrimento da horizontalidade, na essência da Extravagância, corriqueira nas esquizofrenias (Binswanger, 1977). Para Tamelini (2012, p. 8)

A espacialidade também pode ser considerada em relação à preponderância do vetor de afastamento do mundo em detrimento de mecanismos de aproximação, assim como através da sua "consistência" fundamental, como, por exemplo, ora se comportando como dura imposição, resistência, ora como fluidez etérea.

Ou ainda, o poderio desmedido, sem contrapontos, de uma esfera de mundo (como a independência do Mitwelt, responsável pela "mundanização" da existência no caso Jurg Züntd).

A perda da saudável dialética estrutural, de proporções dinamicamente montadas, também pode ser vista em outras vertentes. Uma delas é o desequilíbrio da "natureza" em relação às determinações "espirituais" do homem. A patologia "na verdade metamorfoseia o homem em sua natureza de criatura... não lhe deixa nenhuma possibilidade de se comportar de outra forma nem de decidir de outra forma" (Tatossian, 2006, p. 316). Assim, pode-se pensar em um desequilíbrio entre a capacidade de se auto-determinar e as condições impostas à existência pela sua natureza, tal como mostrado no caso Ellen West: há uma "progressiva solidificação ou coagulação do 'si-mesmo' livre, em direção a um estado cada vez menos livre (dependente), no qual, a autonomia vai sendo retirada do ser, o ser é amplamente mundanizado e transformado em coisa" (Binswanger, 1968, p. 182) e "a liberdade se transforma cada vez mais em coação e obrigação e a existência, em um acontecimento forçoso" (Binswanger, 1968, p. 182).

Ainda que breves, essas apreciações estruturais do processo ajudam a compreender melhor a evolução grave que a psicopatologia jasperiana reconhece e categoriza. A fibrose estável, em um estado de desarticulação temporoespacial, marca o processo, mas não exclui a possibilidade de haver simultaneamente zonas divergentes, nas quais se pode observar uma genuína perspectiva de mudança. Ao detectar a heterogeneidade da temporalidade, com zonas processuais coexistindo com outras dissonantes, pode-se buscar estratégias terapêuticas mais consistentes com o desenho microscópico, mais específicas, seja do ponto de vista farmacológico, seja psicoterapêutico, sem desconsiderar seus riscos inerentes. 
Assim, as categorias biográficas passam a ser não um veredito estático, que condena a priori a uma evolução reservada, mas um reparo de ordem longitudinal, macroscópico, útil no árduo trabalho clínico em prol de alguma movimentação psíquica na engessada estrutura da patologia.

\section{Conclusão}

O diálogo entre os conceitos consolidados da Psicopatologia Clínica e as categorias fenomenológicas proporciona refinamento psicopatológico e, no caso do processo psíquico, permite lançar nova luz às formas típicas de aparecimento do fenômeno mental no curso histórico. A visada estrutural pode ampliar noções clínicas, ao reconhecer sua essência fundamental, concebendo transições menos absolutas entre as distintas categorias psiquiátricas. E, como decorrência natural, ajudar na elaboração de estratégias terapêuticas mais precisas e sofisticadas.

\section{Referência Bibliográficas}

Alonso-Fernández, F. (1979). Proceso y Desarollo. In: Fundamentos de La Psiquiatria Actual - Tercera Edicion. Editorial Paz Montalvo.

Andreasen, N. C. (2007). DSM and the Death of Phenomenology in America: An Example of Unintended Consequences. Schizophrenia Bulletin, 33 (Q), 108 $-112$.

Biswanger, L. (1968). El caso Ellen West: estúdio antropológico-clínico. In: Existencia. Nueva Diménsion en Psiquiatria y Psicología. Madrid: Editorial Gredos. . (2005). Mélancolie et Manie. Paris, PUF. (1977). Três Formas da Existência Malograda. Rio de Janeiro, Zahar Editores.

Blakenburg, W. (1982). A dialectical conception of anthropological proportions. In: De Koonig, A. Jenner, F., editors. Phenomenology and Psychiatry (pp. 35-50). London: Academic Press. 
Charbonneau, G. (2010). Introduction à la Psychopathologie phénoménologique. Paris: MJM Fédition.

Climent, M. V. (2003). Para ler a Jaspers: Invitación a la Psicopatolgía General. Santiago de Chile: Editorial Universitaria.

Dörr Zegers, O. (1995). Psiquiatría Antropológica: contribuciones a una psiquiatría de orientación fenomenológica-antropológica. Santiago de Chile: Universitária.

Jablensky, A. (2013). Karl Jaspers: Psychiatrist, Phisopher, Humanist. Schizophrenia Bulletin, 39 (2), 239-241.

Jaspers, K. (2000). Psicopatologia Geral. São Paulo: Editora Atheneu. (1977). Escritos Psicopatológicos. Madrid: Ed. Gredos.

Lanteri-Laura, G. (1982) Phenomenology and a critique of the foundations of psychiatry. In: De Koonig, A. Jenner, F., editors. Phenomenology and Psychiatry (pp. 51-62). London: Academic Press.

Messas, G. P. (2004). Psicopatologia e Transformação: um esboço fenômeno-estrutural. São Paulo: Casa do Psicólogo.

. (2010). Ensaio sobre a estrutura vivida. São Paulo: Roca.

Minkowski, E. (2000). La Esquizofrenia: psicopatologia de los esquizóides y los esquizofrénicos. México, D. F.: Fondo de Cultura Económica.

(2005). Le temps vécu. Études Phénoménologiques et Psychopathologiques. Paris, PUF.

Tamelini, M. G. (2012). Cinética Estrutural na Esquizofrenia. In: Revista de Psicopatologia Fenomenológica Contemporânea, 1, 3-25.

Tatossian, A. (2006). A Fenomenologia das Psicoses. São Paulo: Escuta.

Walker, C. (1991). Delusion: What Did Jaspers Really say? British Journal of Psychiatry, 159 (suppl. 14), 94-103. 